Ukraine with highly skilled personnel.

The ensuring employment at the present stage of economic development is one of the most difficult problems. Socio-economic development of rural areas is one of the priority directions of the development strategy of most developed cranes in the world. It was established that in the Ukrainian agriculture there are conflicting changes that negatively affect the employment of rural population.

Negative trends in employment in the rural areas of Ukraine indicate a process of narrowing the scope of rural labor in recent years. As a result, there is an increase in unemployment in these areas. The release of labor from the agricultural sector is accompanied by the appearance of hidden unemployment. The influence of agroholdings on the rural labor market is considered. It is established that activities of agroholdings lead to both positive and negative consequences for employment of the rural population. In addition, in rural areas, there are limited possibilities for providing non-agricultural labor to the population. There were destructive trends in the field of training specialists for the agricultural sector. There is a shortage of skilled personnel for agriculture. Human resources policy in the field does not meet the needs of the modern economy. These processes are an objective prerequisite for further deterioration of the conditions of reproduction of employment in the countryside.

The foregoing stipulates the need for further studies of the identified problem in several directions. First, the definition of the mechanisms of transition from monostructure to polystyrene employment in the countryside. Secondly, the revival and further development of mechanisms for stimulating small businesses in the countryside through the use of opportunities for a cooperative trend. Thirdly, the formation of investment-friendly conditions for the development of rural entrepreneurship. Fourthly, improvement of the training system for the needs of rural areas in accordance with the tasks of regulation of the rural labor market. Fifthly, an assessment of the prospects for expanding rural employment in order to prevent the spread of unemployment in the countryside.

Key words: rural population, employment, unemployment, agroholding, informal employment.

УДК 621.791 .927 .55

\title{
О.Ю. Нестеров
}

\section{ЕКОЛОГО-ЕКОНОМІЧНИЙ РОЗРАХУНОК ПАРАМЕТРІВ УПРАВЛІННЯ ВІДХОДАМИ ПОЛІМЕРНИХ МАТЕРІАЛІВ}

В даній статті аналізуються деякі економічні заходи екологічно чистої утилізації відходів полімерних матеріалів, показана перспективність розвитку теорії та технологій екструдування. Метою даної роботи була розробка екологоекономічного чистого способу управління відходами вторинних полімерів за рахунок вдосконалення роботи екструдера иляхом визначення необхідних конструктивних параметрів шнека. За допомогою аналітичного розгляду процесу екструдування в різних зонах екструдера, які характеризуються різними температурними умовами та насосним ефектом, визначені оптимальні параметри процесу екструдування.

Ключові слова: економічні заходи, екологічно чиста утилізація, екструдування, полімерні матеріали, шнек, оптимальні параметри.

DOI 10.34079/2226-2822-2019-9-17-18-25 
Постановка проблеми. Проблема управління відходами набула сьогодні глобального характеру, і іï ефективне рішення стає одним з ключових чинників для стійкого розвитку суспільства, як з точки зору екологічної безпеки, так і з точки зору збереження природних ресурсів.

Ріст виробництва полімерних матеріалів (більш ніж $3 \cdot 10^{8}$ тон пластичних мас) у світі призводить до виникнення проблеми утилізації їх відходів, а відповідно і до загрози забруднення довкілля. [1,2]. Проблема управління відходами набула сьогодні глобального характеру, і іï ефективне рішення стає одним з ключових чинників для стійкого розвитку суспільства, як з точки зору екологічної безпеки, так і $з$ точки зору збереження природних ресурсів. Прогресуюча освіта i накопичення відходів породжують комплекс взаємозв'язаних ризиків, які в цілому торкаються як умов життєдіяльності людей, так і зрештою їх економічного благополуччя. Сьогодні існує проблема недооцінки вторинної сировини в природно ресурсному потенціалі. Не інформованість і відсутність маркетингу вторинних ресурсів, зневага соціальними і екологічними чинниками i навіть, в деякій мірі, безгосподарність значна частина відходів, які можуть бути використані як матеріальні і енергетичні ресурси, втрачається.

Аналіз останніх досліджень і публікацій. В Україні налічується зараз близько 100 підприємств, які здійснюють утилізацію відходів полімерних матеріалів. На ринку вторинних полімерних матеріалів доцільно виділяти дві групи підприємств. Одна з них - підприємства "з традиціями", які супроводять використання вторинної сировини. А друга група - це спеціалізовані новоутворені підприємства, орієнтовані саме на створення і використання вторинної сировини. В цілому ринок вторинних полімерних матеріалів $\epsilon$ гнучкішим, ніж ринок макулатури. Останніми роками на ринку вторинних полімерних матеріалів виникла велика кількість підприємств, які створювалися саме для переробки полімерних відходів. Головний напрям діяльності цих підприємств обробка і переробка відходів полімерних матеріалів в регранулят. Відходи полімерних матеріалів сортуються по видах, кольорі, якості матеріалу, проходять процес очищення, подрібнення і тому подібне. Деякі з цих підприємств первинно створювалися як підприємства по збору і заготівлі відходів, але потім напрям їх діяльності розширився саме за рахунок переробки і обробки вторинних полімерів. Головна проблема підприємств по переробці полімерних матеріалів - недолік потужностей внаслідок недоліку сировини. Це підприємство стабільно нарощує об'єми переробки. Головними центрами переробки вторинних полімерних матеріалів $\epsilon$ Київ (орієнтовно 10 підприємств), Одеса (10), Дніпропетровськ (6), Харків (5), що пояснюється концентрацією цих видів ресурсів у великих містах. В Україні чотири області не мають підприємств по переробці полімерів (Тернопільська, Закарпатська, Миколаївська i Сумська обл.).

Розвинені країни вкладають колосальні кошти в заходи по поліпшенню екологічної обстановки і максимальному зниженню побічних ефектів від виробництва. Пріоритетним став екологічний напрям розвитку промисловості :збереження природних ресурсів і чистоти довкілля. Багато провідних компаній зробили ставку на турботу про здоров'я споживача і економічна доцільність такого підходу давно підтверджена. Сьогодні великий попит мають саме екологічно чисті товари, оскільки споживач прагне оточити себе безпечними для здоров'я і якісними речами.

Відомими машинами для переробки термопластичних полімерів є екструдери та термопластавтомати [3,4]. Екструзійний прес [5], містить механізм дозування пресмаси, напрямний пристрій, теплообмінні плити, дистанційні планки та привод, а також вертикальний колектор. Крім того агрегат [3], розташовується по довжині колектора та проходить між магістралями подачі теплоносія і відділений від них 
ізолятором та містить нейтральну зону за зоною нагрівання у вигляді заповнених ізолятором поперечних каналів та зону охолодження.

Для забезпечення якості продукції, даний пристрій передбачає розділення на зони (по температурі) по шляху надходження прес-маси, що робиться, в основному, для утворення необхідних фізичних та хімічних якостей (в'язкості) в кожній зоні, а тому i рівного протитиску пресу екструдера. Для забезпечення потрібних температурних умов у зонах пресу використовують хладагенти та теплоносії. Це дуже ускладнює конструкцію пресу екструдера та звужує його технологічні можливості через залежність в'язкості матеріалу та величини протитиску від температури хладагенту та теплоносія, що потребує додаткового використання нагрівачів та холодильників. Двохпозиційний термопластавтомат [6], який складається із станини, в яку вмонтовані два механізми запирання форм, механізм інжекції з черв'ячною пластикацією, а також механізм дотискання. Це дуже обмежує технологічні можливості агрегату i робить його непридатним до використання,а також для переробки великої кількості різновидів полімерів. Також важливим недоліком $є$ час витримки матеріалу під тиском, по відношенню до часу загального циклу виробництва, який може складати до $75 \%$.

Мета статті Довести важливість створення ефективних систем поводження 3 відходами з урахуванням технічних та економічних чинників. Розробка розрахунку та аналітичне дослідження та удосконалення конструкції екструдера для переробки полімерних матеріалів, шляхом визначення потрібних конструктивних параметрів шнека екструдера. Завдяки такій розробці стає можливим покращення умов роботи агрегату та досягається більш повна переробка прес-маси за рахунок вирівнювання протитиску і насосного ефекту у всіх зонах.

Основний матеріал. Одним 3 видів забруднення довкілля $є$ пластикове забруднення, яке негативно впливає на земну поверхню і воду. Пластмаси містять багато хімічних речовин, які негативно впливають на усе живе. Мають місце зусилля із скорочення використання пластмас і їх вторинної переробки. Проте пластмас отримав широке поширення, як матеріал для упаковки, унаслідок своєї довговічності і невисокої ціни. 3 точки зору функціональності, упаковка повинна відповідати ряду принципів, таких як: захист, герметичність, надання інформації, естетичний вигляд, простота використання і усім цим принципам пластмасова упаковка відповідає. Але незважаючи на усі позитивні характеристики ця упаковка має істотний недолік - цей вид відходу переробляти досить проблематично.

Ріст виробництва полімерних матеріалів у світі призводить до виникнення проблеми утилізації їх відходів, а відповідно і до загрози забруднення довкілля. Враховуючи специфічні властивості полімерних матеріалів (вони не піддаються гниттю i корозії) вирішення цієї проблеми носить, передусім, екологічний характер. Універсального рішення цієї проблеми навіть в економічно розвинених країнах доки не знайдено. Причина такого положення обумовлена необхідністю застосування до неї комплексного підходу, що включає соціально-економічну, науково-технічну і інші складові. В даний час в суспільстві діє схема «здобич - переробка - вживання - відходи» але вона стає нині усе менш прийнятної внаслідок недостатнього дефіциту землі та ресурсів потрібних для поховання відходів.

Екструдування $€$ одним із екологічно чистих методів переробки вторинних полімерів на даний час. Головним елементом у конструкції екструдера $є$ шнек який повинен конструюватись таким чином, щоб продуктивність кожної зони екструдера була рівномірною. Шнек виготовляється цільним, це підвищує надійність роботи агрегата. Пресована маса перетворюється із твердої на в'язку суміш яка має різноманітні фізичні характеристики. Протитиск екструдера, у випадку однакового кута 
нахилу робочої вісі шнека, різний у кожній зоні, що викликає неоднаковий розподіл тиску та різну продуктивність у кожній зоні.

Визначення величини кута нахилу робочого каналу шнека, в залежності від протитиску агрегата, дозволяє вирівнювати насосний ефект та продуктивність у кожній зоні екструдера. Зміна кута нахилу робочого каналу у кожній зоні призведе до покращення якості виробів, виключення їх різнотовщинності, а також обривів у процесі роботи.

Розглядали схему екструдування (рис. 1).

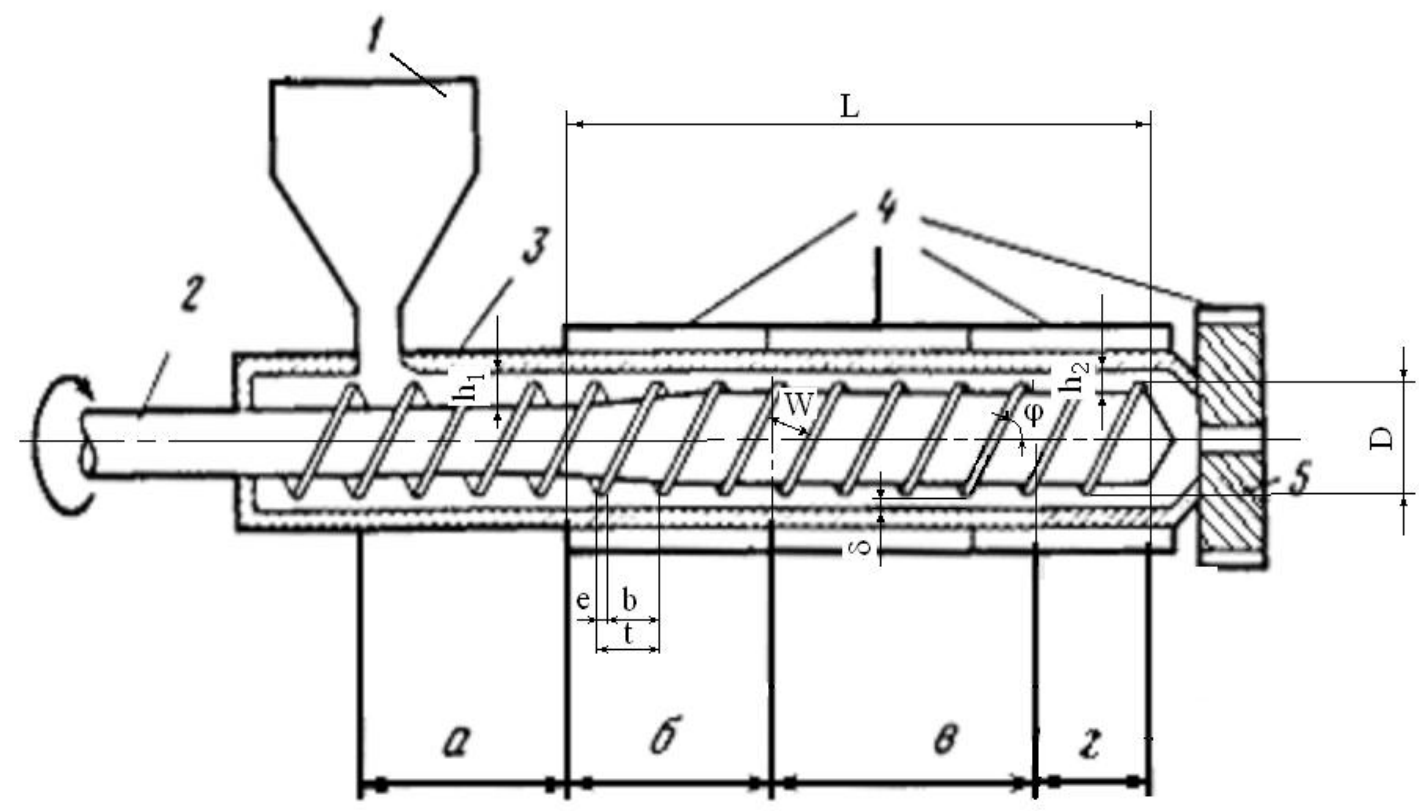

Рис. 1. Схема процесу екструдування для визначення протитиску екструдеру

Записували вираз для визначення протитиску екструдеру у кожній зоні, відповідно до роботи [8]:

$$
\Delta \mathrm{P}=\int_{0}^{L} \frac{\pi^{2} \cdot D^{2} \cdot\left[\left(\frac{h_{2}-h_{1}}{L}\right) \cdot \ell+h_{1}\right] \cdot\left(1-\frac{m \cdot e}{t}\right) \cdot \sin \varphi \cdot \cos \varphi \cdot N \cdot\left[f_{y m}-\frac{\delta}{\left(\frac{h_{2}-h_{1}}{L}\right)}\right] \cdot k_{t} \cdot \eta \cdot(n+1) \cdot 2^{n}}{\pi \cdot D \cdot 2 \cdot f_{n p} \cdot\left(1-\frac{m \cdot e}{t}\right) \cdot \sin ^{n} \varphi \cdot\left[\left(\frac{h_{2}-h_{1}}{L}\right) \cdot \ell+h_{1}\right]^{3}} d \ell,
$$

де $\varphi$ - кут нахилу гвинтового каналу черв'яка шнека у визначеній зоні, град.;

$\Delta P$ - протитиск екструдера у визначеній зоні, Па;

$n$ - індекс плину матеріалу;

$D$ - діаметр шнека у визначеній зоні, м;

$L$ - довжина визначеної зони шнека, м;

$N$ - частота обертання шнека екструдера, $\mathrm{c}^{-1}$;

$k_{t}$ - коефіцієнт впливу температури;

$\eta-$ в'язкість прес-маси при завданих температурно-швидкісних умовах, Па·с;

$f_{y m}-$ коефіцієнт впливу втрат; 
$f_{n p}-$ коефіцієнт впливу протитоку;

$B=\frac{h_{2}-h_{1}}{L}-$ коефіцієнт, що враховує конічний нахил зони шнека;

$h_{1}$ та $h_{2}$ - товщини шару матеріалу на вході та виході у визначеній зоні екструдера, м;

$e-$ товщина гвинта черв'яка шнека, м;

$\delta$ - зазор між гвинтом черв'яка та корпусом, м;

$\mathrm{L}=\mathrm{L}_{a}, \mathrm{~L}=\mathrm{L}_{\sigma}, \mathrm{L}=\mathrm{L}_{6}$, та $\mathrm{L}=\mathrm{L}_{2}$ відповідно для кожної зони;

$\ell$ - координата в здовж осі екструдера;

$\mathrm{m}$ - число (кількість) заходів шнека, шт.

Звідки, після скорочень та перетворень виразу (1), запишемо:

$$
\Delta \mathrm{P}=A \cdot \int_{0}^{L} \frac{\left(f_{y m}-\frac{\delta}{\left(\frac{h_{2}-h_{1}}{L}\right) \cdot \ell+h_{1}}\right)}{\left[\left(\frac{h_{2}-h_{1}}{L}\right) \cdot \ell+h_{1}\right]^{2}} d l,
$$

де $A=\frac{\pi \cdot D \cdot \cos \varphi \cdot N \cdot k_{t} \cdot \eta \cdot(n+1) \cdot 2^{n}}{2 \cdot f_{n p} \cdot \sin ^{n-1} \varphi}$,

або $A=C \cdot \frac{\cos \varphi}{\sin ^{n-1} \varphi}$,

тут $C=\frac{\pi \cdot D \cdot N \cdot k_{t} \cdot \eta \cdot(n+1) \cdot 2^{n}}{2 \cdot f_{n p}}$.

Вирішимо інтегральний вираз (2):

$$
\begin{gathered}
\Delta P=A \cdot\left[f_{y m} \int_{0}^{L} \frac{d \ell}{\left(B \cdot \ell+h_{1}\right)^{2}}+\delta \int_{0}^{L} \frac{d \ell}{\left(B \cdot \ell+h_{1}\right)^{3}}\right]=A \cdot\left[\left(-\frac{f_{y m}}{\left(B \cdot L+h_{1}\right)}-\frac{\delta}{2 \cdot\left(B \cdot L+h_{1}\right)^{2} \cdot B}\right)-\left(-\frac{f_{y m}}{h_{1} \cdot B}-\frac{\delta}{2 \cdot h_{1}^{2} \cdot B}\right)\right]= \\
=A \cdot\left[-\frac{1}{\left(B \cdot L+h_{1}\right)} \cdot\left(f_{y m}+\frac{\delta}{2 \cdot\left(B \cdot L+h_{1}\right)}\right)+\frac{1}{h_{1} \cdot B} \cdot\left(f_{y m}+\frac{\delta}{2 \cdot h_{1}}\right)\right]=-\frac{A}{\left(B \cdot L+h_{1}\right)} \cdot\left(f_{y m}+\frac{\delta}{2 \cdot\left(B \cdot L+h_{1}\right)}\right)+ \\
+\frac{A}{h_{1} \cdot B} \cdot\left(f_{y m}+\frac{\delta}{2 \cdot h_{1}}\right)=\frac{A}{B} \cdot\left[\frac{2 \cdot f_{y m} \cdot h_{1}+\delta}{2 \cdot h_{1}^{2}}-\frac{f_{y m}+\frac{\delta}{2 \cdot\left(B \cdot L+h_{1}\right)}}{L+\frac{h_{1}}{B}}\right],
\end{gathered}
$$

де $B=\frac{h_{2}-h_{1}}{L}$.

У загального випадку отримаємо:

$$
\Delta P=\frac{C \cdot \cos \varphi}{B \cdot \sin ^{n-1} \varphi} \cdot\left[\frac{2 \cdot h_{1} \cdot f_{y m}+\delta}{2 \cdot h_{1}^{2}}-\frac{f_{y m}+\frac{\delta}{2 \cdot\left(B \cdot L+h_{1}\right)}}{L+\frac{h_{1}}{B}}\right] .
$$

За даними джерела [8], значення індексу плину матеріалу для полімерних матеріалів знаходиться у межах $\mathrm{n} \cong 2 \ldots 5$. Для конкретного полімеру із $\mathrm{n}=2$, запишемо 
параметри:

$$
C=\frac{6 \cdot \pi \cdot D \cdot N \cdot k_{t} \cdot \eta}{f_{n p}} \quad \text { та } \quad A=\frac{6 \cdot \pi \cdot D \cdot N \cdot k_{t} \cdot \eta \cdot \cos \varphi}{f_{n p} \cdot \sin \varphi}
$$

Введемо тут додаткову величину:

$$
\begin{array}{r}
E=\frac{C}{B} \cdot\left[\frac{2 \cdot f_{y m}+\delta}{2 \cdot h_{1}^{2}}-\frac{f_{y m}+\frac{\delta}{2 \cdot\left(B \cdot L+h_{1}\right)}}{L+\frac{h_{1}}{B}}\right]= \\
=\frac{6 \cdot \pi \cdot D \cdot N \cdot k_{t} \cdot \eta}{f_{n p} \cdot B} \cdot\left[\frac{2 \cdot h_{1} \cdot f_{y m}+\delta}{2 \cdot h_{1}{ }^{2}}-\frac{f_{y m}+\frac{\delta}{2 \cdot\left(B \cdot L+h_{1}\right)}}{L+\frac{h_{1}}{B}}\right] .
\end{array}
$$

Тоді:

$$
\Delta P=E \cdot \frac{\cos \varphi}{\sin \varphi}=E \cdot \operatorname{ctg} \varphi
$$

Звідки, для конкретного полімеру із індексом плину $\mathrm{n}=2$, одержимо:

$$
\varphi=\operatorname{arcctg} \frac{\Delta P}{E} .
$$

Взагалі для розв'язання поставленої в статті задачі запропонована екологічна модель шнека екструдера. Вона складається із обігрівального корпусу 3 завантажувальним отвором, екструзійну голівку, а також черв'ячний шнек із робочим гвинтовим каналом. При конкретизуванні розрахунків використовували експериментальні дані за джерелами $[7,8]$.

Звідки за розрахунками для загального випадку можно встановити оптимальні значення кутів нахилу гвинтового робочого каналу: для зони завантаження $\varphi_{(a)}=85,5$ град., для зони стискання $\varphi_{(\text {) }}=84,3$ град., для зони гомогенізації $\varphi_{(8)}=89,3$ град., для зони дозування $\varphi_{(2)}=88,5$ град. Виконання шнека екструдера із розрахованими значеннями кутів нахилу гвинтового робочого каналу по зонах забезпечить рівний протитиск по всіх зонах агрегату. Виготовлення гвинтового шнеку можливо методами лиття, штампування або накатування по ділянках.

Висновки. В статті показана еколого-економічна перспективність напряму комплексного розвитку технології переробки вторинних полімерів, кількість яких 3 кожним роком збільшується. Для переробки та повторного використання термопластичних полімерів найбільш придатним та універсальним є способ екструзії (соекструзії). Для покращення якості продукції $\mathrm{i}$ розширення технологічних можливостей екструдеру вирівнювання протитиску прес-маси, встановлен вираз для визначення необхідного кута нахилу гвинта шнеку, що потрібно враховувати при виготовленні та експлуатації машини. Розроблено методику розрахунку економічного конструювання параметрів шнеку екструдеру та наведений приклад розрахунку для конкретного випадку, що відповідає умовам переробки поліетилену низького тиску.

\section{Список використаної літератури}

1. Филатов В. А. Вредные вещества в промышленности. Справочник / под общ. ред. В. А. Филатова, В. А. Курляндского. - Ленинград : Химия, 1993. - 463 с. ; Filatov V. A. Vrednye veshchestva v promyshlennosti. Spravochnik / pod obshch. red. V. A. Filatova, 
V. A. Kurlyandskogo. - Leningrad : Khimiya, 1993. - 463 s.

2. Дядичев В. В. Соекструзійна обробка вторинних полімерних матеріалів (теорія, технологія, обладнання) : автореф. дис... докт. техн. наук : спец. 05.03 .05 / Валерій Володиславович Дядичев; Східноукраїнський національний ун-т ім. В. Даля. Луганськ, 2003. - 36 c. ; Diadychev V. V. Soekstruziina obrobka vtorynnykh polimernykh materialiv (teoriia, tekhnolohiia, obladnannia) : avtoref. dys... dokt. tekhn. nauk : spets. 05.03.05 / Valerii Volodyslavovych Diadychev; Skhidnoukrainskyi natsionalnyi un-t im. V.Dalia. - Luhansk, 2003. - 36 s.

3. Торнер Р. В. Оборудование заводов по переработке пластмасс: учеб. пособ. / Р.В. Торнер, М. С. Акутин. - Москва : Химия, 1986. - 400 с. ; Torner R. V. Oborudovanie zavodov po pererabotke plastmass: ucheb. posob. / R. V. Torner, M. S. Akutin. - Moskva : Khimiya, 1986. - 400 s.

4. Басов Н. И. Оборудование для производства объемных изделий из термопластов / Н. И. Басов, В. С. Ким, В. К. Скуратов. - Москва : Машиностроение, 1972. - 272 c. ; Basov N. I. Oborudovanie dlya proizvodstva obemnykh izdeliy iz termoplastov / N. I. Basov, B. C. Kim, V. K. Skuratov. - Moskva : Mashinostroenie, 1972. $272 \mathrm{~s}$.

5. А.c. 2038206 СССР, МПК 6 В 29 N 3/26, 5/02. Экструзионный пресс / Г. Я. Жибуль (СССР). - № 8344921, заявл. 20.08.1991, опубл. 21.05.1993, Бюл. № 19.; A.s. 2038206 SSSR, MPK 6 V 29 N 3/26, 5/02. Ekstruzionnyy press / G. Ya. Zhibul (SSSR). - № 8344921, zayavl. 20.08.1991, opubl. 21.05.1993, Byul. № 19 .

6. А.c. 188654 СССР, МПК 4 В 29 F, 3/00. Двухпозиционный термопластавтомат / Э.Л. Калиничев, И.С. Кричевер, Т.П. Николенко, И.М. Рабинович. - № 793085/23-5, заявл. 03.09.1962, опубл. 01.11.1966, Бюл. 22.; А.s. 188654 CCCR, MPK 4 V 29 F, 3/00. Dvukhpozitsionnyy termoplastavtomat / E.L. Kalinichev, I.S. Krichever, T.P. Nikolenko, I. M. Rabinovich. - № 793085/23-5, zayavl. 03.09.1962, opubl. 01.11.1966, Byul. 22.

7. Шенкель Г. П. М. Влияние результатов исследовательских работ на конструкцию шприц-машины / Г. П. М. Шенкель // Переработка полимеров: сб. пер. / под ред. Р. В. Торнера. - Ленинград; Москва : Химия, 1964. - С. 9-81 ; Shenkel G. P. М. Vliyanie rezultatov issledovatelskikh rabot na konstruktsiyu shprits-mashiny / G. P. M. Shenkel // Pererabotka polimerov: cb. per. / pod red. R. V. Tornera. - Leningrad; Moskva : Khimiya, 1964. - S. 9-81.

8. Якоби Г. Р. Механизм течения в одночервячной шприц-машине / Г. Р. Якоби // Переработка полимеров : сб. пер. / под ред. Р. В. Торнера. - Ленинград; Москва : Химия, 1964. - C. 105-127 ; Yakobi G. R. Mekhanizm techeniya v odnochervyachnoy shprits-mashine / G. R. Yakobi // Pererabotka polimerov : cb. per. / pod red. R. V. Tornera. Leningrad; Moskva : Khimiya, 1964. - S. 105-127.

Стаття надійшла до редакції 07.04.2019.

\section{O.Yu. Nesterov}

\section{ECOLOGICAL AND ECONOMIC MANAGEMENT OF POLYMERIC MATERIAL WASTES}

In this article some economic measures of ecologically pure utilization of waste of polymeric materials are analyzed, the perspective of development of the theory and extrusion technologies is shown. The purpose of this work was the development of ecological and economic clean way of waste secondary polymers management by improving the work of the extruder by determining the necessary structural parameters of the screw. 
The purpose of this work was an analytical research of backpressure at different sectors of the extruder during the moving through it a pressed bulk and improving of the working conditions of the device in relation to the technology of plastics waste processing. The recommendations to the calculation of the required design parameters of screw, as the main structural element of the extruder, are developed as result of research, which allows to achieve a more complete processing of the pressed bulk under specified temperature and rate conditions due to the alignment of the backpressure and pumping effect in all areas of the device. The proposed enhancement provides of productivity alignment by zones of the extruder, which excludes of intermittent work, breaks and thickness unevenness of manufactured products. Thus, in order to solve the problem set forth in the article, the model of the extruder structure, which includes a heating box with a loading hole and an attached bunker, an extrusion head and a worm screw with a screw channel connected through a gear with an electric drive, is proposed, with the worms A screw auger is designed with integer with two or more zones, and the angle of inclination of the screw channel in each zone. When specifying the calculations, experimental data from sources were used.

How to calculate the transcendental equation for a general case, it is easy to determine the values of the angles of inclination of the propellant channel: for the loading zone, for the zone of homogenization, for the zone of dosing. Execution of a screw extruder with determined values of angles of inclination of the screw channel along the zones will provide even counterpressure in all areas of the extruder. Manufacturing of a screw is possible by methods of molding, stamping or rolling on sections. By the analytical consideration of the theory of the extrusion process in the various sectors of the extruder, which are characterized by different temperature conditions and the pumping effect, is obtained of equation for calculating of the auger screw inclination angle for each sector of extruder that allows to improve of the machine design. The example of calculation of the screw design parameters for physical and chemical characteristics of low-pressure polyethylene under the conditions of its processing is made.

Key words: economic measures, environmentally friendly utilization, extrusion, polymer materials, screw, optimal parameters.

УДК 332.12-049.5(477-62)

\section{O. В. Захарова}

\section{ЗАБЕЗПЕЧЕННЯ ЕКОНОМІЧНОЇ БЕЗПЕКИ РЕГІОНІВ В УМОВАХ НЕСТАБІЛЬНОГО ЗОВНІШНЬОГО СЕРЕДОВИЩА}

Стаття висвітлює практичні аспекти забезпечення економічної безпеки на рівні регіону та міста в умовах посилення нестабільності зовнішнього середовища. Автор акцентує увагу на загрозах економічній безпеці територій Сходу України, що опинилися в зоні військово-політичного конфлікту. На прикладі крупного промислового міста Маріуполя визначено основні загрози економічної безпеки та обтрунтовано чинники, щзо обумовлюють їх прояви та характер діï.

Ключові слова: економічна безпека, регіони, нестабільність, воєнний конфлікт, загрози, Донецька область, Маріуполь.

DOI 10.34079/2226-2822-2019-9-17-25-40

Постановка проблеми. В умовах стрімкої зміни геополітичних реалій та ведення військових дій на територіях східних регіонів України особливої актуальності набирає 